\title{
Visual imagery mnemonics: Common vs. bizarre mental images
}

\author{
PAUL D. HAUCK, CAROL C. WALSH, and NEAL E. A. KROLL \\ University of California, Davis, California 95616
}

\begin{abstract}
Earlier tests of the effectiveness of bizarre imagery failed to support its claimed superiority, but also failed to use experienced subjects. Since it could be argued that experience differentially improves bizarre imagery, either directly by improving the quality of the bizarre image or indirectly by increasing the interference among common images, the present experiment required five sessions. While subjects improved in their speed of forming images over the five sessions, common images retained their speed advantage and no difference was found between the recall of word pairs learned by bizarre images and those learned by common images on any of the 5 days.
\end{abstract}

Professional mnemonists have claimed for centuries that visual imagery mnemonics are most effective when the mental images formed are as bizarre as possible. Now that mnemonic techniques have again captured the public interest, the claims favoring bizarre imagery are being renewed. Lorayne and Lucas (1974, p. 9), in their nationwide bestseller, claim "... you need a ridiculous-impossible, crazy, illogical, absurd-picture or image to associate the two items. What you don't want is a logical or sensible picture." Life Cereal's Brain Builders, Lesson 15, asserts "The sillier the picture, the easier to remember." With an apparent unanimity among professional mnemonists concerning the advisability of bizarre imagery, one would expect that it would be an easy task to demonstrate the superiority of bizarre over common imagery in the laboratory. However, despite many attempts, no such laboratory support is available.

Nappe and Wollen (1973) critically reviewed the relevant research and developed a procedure which should have avoided many of the earlier pitfalls. They used 48 paired nouns as memory items, directed subjects to form either bizarre or common images with them, and recorded a description of the images which were later scored for degree of bizarreness. A recall test of the word pairs revealed no difference in recall rate between pairs associated with bizarre and common images. In addition, the bizarre images took longer to form, indicating that they may be an even less efficient type of mnemonic. The same result was obtained when only those images rated as extremely bizarre or extremely common were scored.

The absence of an advantage for bizarre imagery

This research was supported by the University of California. The first author is now at the University of the Pacific. The authors are indebted to Kenneth Ransford and to Heide Hoffner for their assistance in collecting and analyzing data. Requests for reprints should be sent to Neal E. A. Kroll, Department of Psychology, University of California, Davis, California 95616. among these subjects may have been due to their lack of prior experience in using mental imagery. They may have had difficulty in forming clear bizarre images or it may be that the only value of bizarre images to the mnemonist is that they are more distinct and easily separable from previously formed images. The present study attempts to incorporate the strengths of the Nappe and Wollen (1973) experiment but, in addition, seeks to determine the effects that practice may have in producing superior recall for bizarre imagery.

\section{METHOD}

The subjects were 48 students currently enrolled in introductory psychology courses who were given extra credit for their participation. Subjects were required to be present on 5 consecutive days.

The materials consisted of five decks of $483 \times 5$ in. cards, on each of which was typed a noun pair. A list of 48 cue words provided the first half of every pair, so that each cue word appeared one time each day. On each card the cue word was paired with a different memory word, so that each memory word appeared only once during the week. Cue words and memory words were drawn from the list compiled by Paivio, Yuille, and Madigan (1968) and had minimum ratings of 5.00 for imagery. The nouns were paired such that, in the opinion of the experimenters, both bizarre and common images could readily be formed for each.

Subjects were told to form either a common or a bizarre image for each pair. The type of image to be formed for a given card was indicated by a " $C$ " or a " $B$ " written on a lower corner of the card. (Each card had opposite letters on its lower corners. The experimenter covered the left corner while showing the cards to half of the subjects and covered the right corner while showing them to the other half.) The Cs and Bs were assigned to cue words in such a way that a given subject had the same imagery condition for a given cue word for the first 4 days; 24 of the cue words were Cs and 24 Bs. On the 5th day, the Cs and Bs for half of each of these groups of cue words were reversed (with different halves reversed for different subjects), yielding four conditions for each subject based on the type of imagery and cue word pairings: those cue words with common imagery for all 5 days (CC), common for 4 days and bizarre on the 5 th (CB), bizarre for all days (BB), and bizarre for 4 days and common on the 5th (BC). In addition to using two different pairings of cue words and type of imagery 
Table 1

Average Percentage of Words Recalled from Each Day's List as a Function of Imagery Instruction

\begin{tabular}{lcccccc}
\hline & \multicolumn{7}{c}{ Day } \\
\cline { 2 - 7 } & 1 & 2 & 3 & 4 & 5 & Total \\
\hline Recalled & & & & & & \\
$\quad$ Common & 8.5 & 8.5 & 9.0 & 17.1 & 66.5 & 21.9 \\
$\quad$ Bizarre & 9.0 & 8.2 & 9.8 & 15.2 & 68.0 & 22.0 \\
Recalled Correctly by Day & & & & \\
$\quad$ Common & 4.1 & 2.4 & 4.0 & 10.9 & 64.8 & 17.3 \\
$\quad$ Bizarre & 4.0 & 3.1 & 4.3 & 11.9 & 65.3 & 17.7 \\
\hline
\end{tabular}

across subjects and two different reversal patterns on Day 5, four different noun pair sequences were employed.

The instructions and examples were similar to those used by Nappe and Wollen (1973). In particular, subjects were informed that the purpose of the experiment was to measure the effect of practice on their ability to form images and were not told that it was a memory experiment. This ruse was to prevent rehearsing and other techniques used to improve memory that are unrelated to the purpose of this experiment.

The experimental session each day consisted of presenting the subject with the noun pairs, one at a time, recording the latency to the nearest $.1 \mathrm{sec}$ of the key response which indicated that an image had been formed, and recording a description of each image. Unlike the Nappe and Wollen (1973) experiment, subjects were allowed an unlimited amount of time to form images, but it was rare that an image took longer than $30 \mathrm{sec}$. On the 5 th day the image session was followed by a filler task which consisted of completing a questionnaire which required the subject to rate the difficulty in forming images, to rate the distinctiveness between his common and bizarre images, and to state a belief about the purpose of the experiment. After the questionnaire was completed, the recall test was administered.

The recall test consisted of a form containing the 48 cue words with five blank spaces next to each, one for the word paired with the cue word on each day. If the subject remembered a word but was unsure of the day it was presented, the word was to be written in any blank space following the proper cue word, but circled to indicate a lack of order.

At the end of the experiment, the records of the image descriptions for the 5 th day were rated independently by three judges on a 6-point scale ranging from very common (1) to very bizarre (6). This allowed a comparison of the recall rates of extreme cases and also insured that subjects were following their imagery instructions.

\section{RESULTS}

Allowing unlimited time for the subjects to form a mental image resulted in very few failures to form images. Although at the beginning of the week this meant longer latencies than those found by Nappe and Wollen (1973), by Day 5 they had dropped considerably, but common images retained their speed advantage over bizarre images. On Day 5 the average time required to form images was $3.13 \mathrm{sec}$ under common instructions and $5.92 \mathrm{sec}$ for bizarre, and only 1 subject of the 48 formed bizarre images faster than common images.
Although it w.s expected, on the basis of reports from professional mnemonists, that bizarre images would result in better recall than common images, the percentage of recall was extremely similar following both types of imagery. Table 1 presents the average percentage of memory words recalled from each day's list for common and bizarre imagery instructions. The percentages in the top two rows were obtained by counting a memory word as correctly recalled as long as it was written in the correct row (i.e., following the proper cue word), regardless of whether it was in the correct column (i.e., assigned to the proper day of presentation). Incidently, almost no memory words were recalled in the wrong row. The percentages in the bottom two rows of the table were obtained by counting a memory word as correctly recalled only if it was placed in both the proper row and the proper column. Both methods of scoring found the percentage of recall following the two types of imagery to be virtually identical for each of the 5 days. The much lower recall of words presented on the earlier days is typically found when subjects do not "elaborate" their images by incorporating earlier and later memory words paired with the same cue word into single images (e.g., Bower, 1973). There would be no reason for subjects in this experiment to use this elaboration strategy, since they did not expect a recall test and since few subjects even noticed that cue words were being reused until the third or fourth experimental session.

Intuitively, it seems that items associated via bizarre imagery would be more distinctive than items associated via common imagery. In order to accentuate any such effect, the present experiment required subjects to use common imagery with some cue words for the first four sessions and then switch to bizarre imagery with these cue words on the 5th day. It was thought that the memory words paired with these cue words on the 5th day would have the maximum advantage of distinctiveness gained through the use of bizarre imagery. Table 2 presents the average percentage of words recalled on Day 5 for each of the four experimental conditions (common-common, bizarre-common, bizarre-bizarre, and common-bizarre) both when scoring

Table 2

Average Percentage of Words Recalled of Day 5's List as a Function of Experimental Condition

\begin{tabular}{llccc}
\hline \multicolumn{2}{c}{$\begin{array}{c}\text { Type of Imagery } \\
\text { Instruction }\end{array}$} & & \multicolumn{2}{c}{ Extreme Pairs } \\
\cline { 5 - 6 } & & & & \multicolumn{2}{c}{$\begin{array}{c}\text { Percentage } \\
\text { Days 1-4 }\end{array}$} & Day 5 & & All Pairs & & Extreme & Correct \\
\hline Common & Common & 67.5 & 60.6 & 68.5 \\
Bizarre & Common & 65.5 & 63.2 & 62.6 \\
Bizarre & Bizarre & 70.3 & 36.8 & 61.8 \\
Common & Bizarre & 65.6 & 37.7 & 63.1 \\
\hline
\end{tabular}


all pairs and when scoring only those pairs associated by images that were judged by all three judges to be extremely bizarre or extremely common. Again, percentage of correct recall does not seem to be related to type of imagery.

A questionnaire was used as a distractor task separating the fifth imagery session from the recall task. Subjects rated on a scale of 1 to 5 several characteristics of their mental images throughout the week. These included how clear the image appeared in their "mind's eye," the difficulty in producing the images, how distinctly different common images were rom bizarre ones, and which type of image was the more difficult to produce. The responses of all 48 subjects are summarized in Table 3.

One possibility is that only 4 days of practice made no difference in the differentiation of bizarre and common imagery, but rather that certain people can form clearer images and, thus, can retain the bizarre images longer. It was felt that if only those subjects who indicated on the questionnaire that they had very clear images were separated and analyzed separately, recall for bizarre over common would improve. This division of subjects into clear and unclear images made no difference in the amount or type of recall. In fact, none of the separations provided by the questionnaire responses made any marked difference in recall patterns.

Subjects did not feel that forming images was particularly difficult, especially toward the end of the week. Subjects reported that the distinction between the two types of images was vague. As expected from the latency data, bizarre images were reported to be more difficult to produce than common ones.

\section{DISCUSSION}

While the present experimenters had high hopes that they had the key ingredient-experienced subjects-to produce bizarre imagery superiority, the only effect of experience seemed to be an increased speed of forming both bizarre and common images. The difference in speed, favoring common
Table 3

Summary of All the Responses to the Questionnaire Used as a Distractor

Question

('larity (Dim-Clear)

Difficulty (Hard-liasy)

Distinction (Small-Great)

More Difficult (Bizarre-Common)

\begin{tabular}{rrrrrr}
\multicolumn{9}{c}{ Response } \\
1 & 2 & 3 & 4 & 5 & Total \\
1 & 3 & 6 & 27 & 11 & 48 \\
0 & 1 & 25 & 19 & 3 & 48 \\
0 & 7 & 24 & 14 & 3 & 48 \\
24 & 14 & 7 & 1 & 2 & 48
\end{tabular}

images, remained and no difference in recall rate developed. It is difficult to believe that all the professional mnemonists could be so wrong. It is possible that the present subjects were not experienced enough; however, there were not even any trends developing-not even among those subjects with fast image times who rated their images as very clear. Another possibility is that bizarre imagery is useful in separating images from everyday life (Lorayne \& Lucas, 1974) but that here the experimental situation itself performed this function equally for common and bizarre images. Again, however, one would expect some trends in the present experiment with five lists of 48 pairs occurring in the same setting. As the negative results continue to accumulate, it seems more and more likely that Bower (1970) was correct when he suggested that "any effect ... in naturalistic settings is probably due to incidental factors (for example, arousing or maintaining interest in learning by the novel association)."

\section{REFERENCES}

Bower, G. H. Analysis of a mnemonic device. American Scientist, 1970, 58, 496-510.

Bower, G. H. How to ... uh ... remember! Psychology Today, 1973, 63-70.

Lifie cereal, Brain Builders, Lesson 15. Chicago: Merchandise Mart Plaza, The Quaker Oats Company.

LORAYNe, H., \& Lucas, J. The memory book. New York: Ballantine, 1974

Nappe, G. W., \& Wollen, K. A. Effects of instructions (1) form common and bizarre mental images on retention. Journal of Experimental Psychology, 1973, 100, 6-8.

Paivio, A., Yullle, J. C., \& Madigan, S. A. Concreteness, imagery, and meaningfulness values for 925 nouns. Journal of Experimental Psychology Monograph Supplement, 1968, 76(1, Part 2).

(Received for publication October 20, 1975.) 